\title{
The importance of differentiating between qualitative, semi-quantitative, and quantitative imaging-close only counts in horseshoes
}

\author{
Richard M. Fleming ${ }^{1}$ (D) Matthew R. Fleming ${ }^{1} \cdot$ William C. Dooley $^{2} \cdot$ Tapan K. Chaudhuri $^{3}$
}

Published online: 17 January 2020

(C) Springer-Verlag GmbH Germany, part of Springer Nature 2019

Considerable emphasis is being placed on the introduction of artificial intelligence (AI) and quantification of diagnostic imaging - both for the purpose of initial diagnosis and treatment monitoring. In an era focusing on improving our decision making results, it is important to recognize the difference between qualitative, semi-quantitative and quantitative imaging. Qualitative imaging - the visual review of imaging by a clinician from which a rendering of disease is present or absent-is flawed with errors in finding diseases (sensitivity) and correctly eliminating (specificity) disease.
The focus on quantification has been brought forward by SNMMI, ASNC, and CMS - all calling for quantification of nuclear imaging. This has resulted in the erroneous use of the term quantification for SUV results [1], when at best SUV is a semi-quantitative method [2] — in contrast to true quantification $[3,4]$. These differences can best be appreciated as explained in Table 1 and Fig. 1.

The ability to quantitatively measure the extent of metabolic and regional blood flow differences (RBFDs) makes it possible to determine exactly where (Fig. 2) the patient is on their

Table 1 Characteristics distinguishing three approaches to diagnostic imaging

\begin{tabular}{|c|c|c|c|}
\hline & Qualitative imaging & Semi-quantitative & Quantitative \\
\hline $\begin{array}{l}\text { Results discussed in } \\
\text { scientific literature }\end{array}$ & Sensitivity and specificity errors & Sensitivity and specificity errors & Accurate, consistent, reproducible \\
\hline Calibration & $\begin{array}{l}\text { Camera not quantitatively } \\
\text { calibrated. Interpretation } \\
\text { per human eye }\end{array}$ & $\begin{array}{l}\text { Camera not quantitatively calibrated. } \\
\text { Estimates against something not actually } \\
\text { measured by the imaging device }\end{array}$ & $\begin{array}{l}\text { Camera } I S \text { quantitatively calibrated. } \\
\text { Calibrated to that which the camera } \\
\text { actually measures - scintillation emissions }\end{array}$ \\
\hline Reported as & $\begin{array}{l}\text { Normal, mild, moderate, } \\
\text { severe, absent }\end{array}$ & $\begin{array}{l}\text { Ratios: Derived from time per injected } \\
\text { radiation per patient body weight or } \\
\text { Radiation per gram per volume }\end{array}$ & $\begin{array}{l}\text { Absolute value: Emissions measured and } \\
\text { quantitatively compared with radioactive } \\
\text { decay of isotope }\end{array}$ \\
\hline Interpretation & Subjective & Subjective with various assumptions & Objective \\
\hline $\begin{array}{l}\text { Application to artificial } \\
\text { intelligence }\end{array}$ & $\begin{array}{l}\text { Not applicable given errors } \\
\text { in sensitivity and specificity }\end{array}$ & $\begin{array}{l}\text { Not applicable given errors in } \\
\text { sensitivity and specificity }\end{array}$ & $\begin{array}{l}\text { Already incorporated into } \\
\text { machine-to-machine (M2M)-AI }\end{array}$ \\
\hline
\end{tabular}

This article is part of the Topical Collection on Editorial

\section{Richard M. Fleming}

FHHI-OmnificImaging-Camelot, Los Angeles, CA, USA

2 Oklahoma University Health Science Center Oklahoma City, Oklahoma, USA

3 Eastern Virginia Medical School, Norfolk, VA, USA 


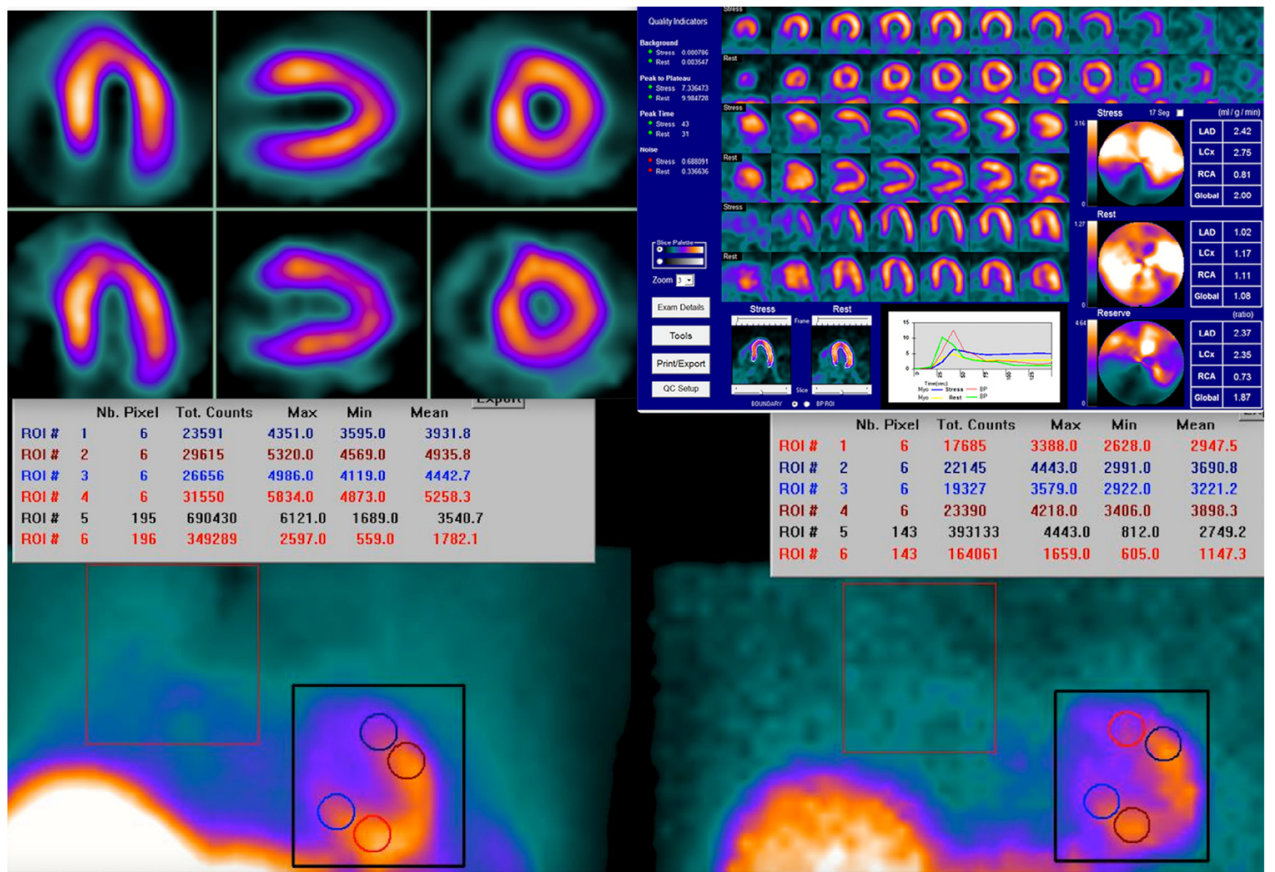

Fig. 1 Comparison of results obtained using three approaches to diagnostic imaging. The upper left panel shows vertical long axis, horizontal long axis, and coronal qualitative results of a myocardial perfusion imaging (MPI) study with comparison sets of images for clinicians to interpret. The upper right panel shows similar displays of images - this time with semi-quantitative estimates of the $\mathrm{ml} / \mathrm{g}$ of tissue/min, which are not something actually measured by PET camerasrequiring a series of assumptions. Finally, the lower half shows true quantification of emitted scintillations measured by FMTVDM following quantitative camera calibration of isotope emissions [3] CELLULAR GENETIC RESPONSE AND ENVIRONMENTAL. INSULT

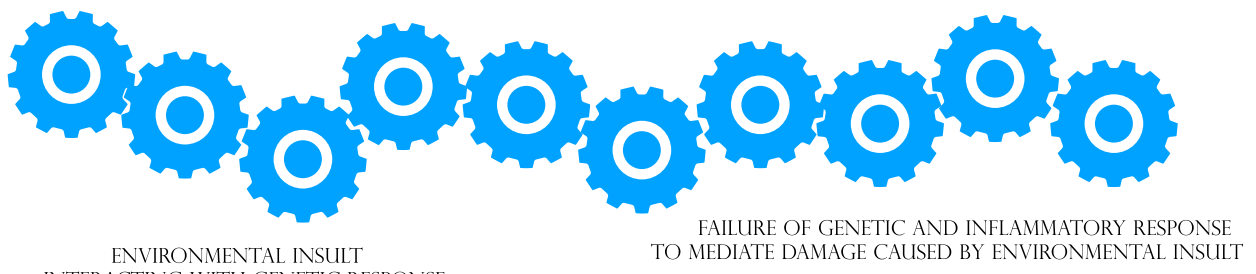
INTERACTING WITH GENETIC RESPONSE
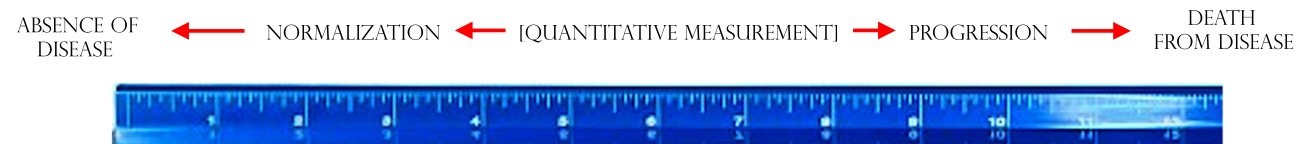

\section{IN CONTRAST TO THE YES/NO - ONE EXTREME OR THE OTHER - PRESENCE OR ABSENCE OF DISEASE} USING QUALITATIVE VISUAL \& SEMI-QUANTITATIVE (SUV, CAC SCORING) ASSUMPTIONS

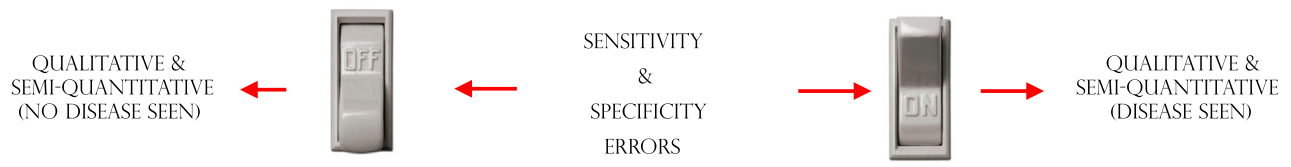

Fig. 2 True quantification makes possible the placement of a patient's health status on a quantitative health-spectrum [4] 
Health-Spectrum [4], providing not only for accurate diagnostics but also the ability to provide patient-specific, patientdirected, and patient-oriented treatment-improving treatment outcomes while reducing time, costs, and lives lost from ineffective or harmful treatments.

\section{Conclusion}

The introduction of tools has separated humanity from the other animal species for thousands of years. The ability to visually determine the extent of a problem precedes the development of tools used to measure the extent of the problem under consideration; measurements which also make possible the exchange of information that is reproducible, consistent, and accurate.

The development of nuclear imaging has seen several changes over the decades; it has been utilized in medical diagnostics, including the visual interpretation and in recent years, semi-quantitative modeling, which is premised upon assumptions thereby limiting its outcomes as noted by the continued publication of sensitivity and specificity data.

True quantification, however, does not miss disease when present and does not attribute disease to be present when it is not. While qualitative and semi-quantification may be closeclose only counts in a game of horseshoes. Close is not acceptable for the practice of medicine and the treatment of patients. True quantification through FMTVDM provides the doorway through which nuclear imaging leaves the world-ofclose behind and enters the scientific realm of true measurement, diagnostics, and treatment monitoring of patients.
Acknowledgments FMTVDM is a utility patent that quantitatively measures changes in metabolism and regional blood flow differences (RBFD) present across the transitional tissue changes occurring in heart disease, cancer and other tissues. It is issued to the first author. Figures reproduced by expressed consent of first author.

\section{Compliance with ethical standards}

Conflict of interest FMTVDM patent issued to primary author.

Research involving human participants and/or animals This article does not contain any studies with human participants or animals performed by any of the authors.

\section{References}

1. Kitajima K, Suenaga Y, Minamikawa T, et al. Clinical significance of SUVmax in 18F-FDG PET/CT scan for detecting nodal metastasis in patients with oral squamous cell carcinoma. SpingerPlus. 2015;4: 718. https://doi.org/10.1186/s40064-015-1521-6.

2. Sheikh A. Evolution of quantification in clinical nuclear medicine: a brief overview of salient uses and upcoming trends. J Nucl Med Radiat Ther. 2018;9(4):1000375. https://doi.org/10.4172/21559619.1000375.

3. The Fleming method for tissue and vascular differentiation and metabolism (FMTVDM) using same state single or sequential quantification comparisons. Patent Number 9566037. Issued 02/14/2017.

4. Fleming RM, Fleming MR. The importance of thinking about and quantifying disease like cancer and heart disease on a "HealthSpectrum" Continuum. J Compr Cancer Rep. 2019;3(1):1-3 (100011).

Publisher's note Springer Nature remains neutral with regard to jurisdictional claims in published maps and institutional affiliations. 